\title{
Diversitas dan Karakteristik Alga Merah (Rhodophyta) pada Akar Mangrove di Teluk Serewe Kabupaten Lombok Timur
}

\author{
${ }^{1} *$ Mursal Ghazali, ${ }^{1}$ Hijjatul Husna dan ${ }^{1}$ Sukiman \\ ${ }^{1}$ Program Studi Biologi, Fakultas Matematika dan Ilmu Pengetahuan Alam \\ Universitas Mataram \\ Jln. Majapahit No. 62 Mataram, NTB, 83125, Indonesia \\ *email: mursalghazali@unram.ac.id
}

Diterima: 12 April 2018 Publish: 28 Juni 2018

\begin{abstract}
Abstrak
Alga merah (Rhodophyta) merupakan tumbuhan tingkat rendah yang umumnya tumbuh melekat pada substrat tertentu seperti pada karang, lumpur, pasir, batu dan benda keras lainnya. Salah satunya melekat pada mangrove yang merupakan kawasan bernutrisi tinggi. Salah satu daerah yang memiliki hutan mangrove cukup luas ialah Teluk Serewe Kecamatan Jerowaru Lombok Timur. Penelitian ini bertujuan untuk mengetahui keanekaragaman jenis dan karakteristik alga merah yang terdapat pada akar mangrove. Pengambilan sampel pada 4 stasiun menggunakan metode purposive sampling dan jelajah pada saat air surut. Jarak pengambilan sampel yaitu $800 \mathrm{~m}$ pada setiap stasiun. Berdasarkan hasil penelitian alga merah yang di peroleh sebanyak 11 spesies yaitu, 4 spesies dari genus Bostrychia, 3 spesies dari genus Caloglossa, 2 spesies dari genus Catenella, 1 spesies dari genus Gelidium, 1 spesies dari genus Stictosiphonia. Karakteristik alga merah yang menempel pada akar mangrove yaitu bentuk talus silindris dan menyerupai daun (blade), percabangan dikotom atau monopodial dengan sel polysiphonous..
\end{abstract}

Kata Kunci: Alga merah, Hutan Mangrove, Lingkungan

\begin{abstract}
Red algae are Thallophyta that generally grow attached to certain substrates such as in coral, mud, sand, and other hard objects. One of them is attached to the mangrove which is a highly nutritious area. One of the forests that have mangrove forest is quite wide is Serewe Village, Jerowaru District East Lombok. This study aims to determine the diversity of species and red algae characteristics found in mangrove root. Sampling at four stations using purposive sampling method and roaming at low tide. The distance of sampling is $800 \mathrm{~m}$ at each station. Based on the results of the study of red algae obtained as many as 11 species, namely 4 species of the genus Bostrychia, 3 species of genus Caloglassa, 2 species of genus Catenella, 1 species of genus Gelidium, 1 species of genus Stictosiphonia. Characteristics of red algae attached to mangrove root that forms cylindrical thallus and has branching leaf (blade) dichotomy or monopodial with polysiphonous cells.
\end{abstract}

Keyword :Red Algae, Mangrove Forest and Environment. 


\section{Pendahuluan}

Makroalga merupakan tumbuhan tingkat rendah yang umumnya tumbuh melekat pada substrat tertentu seperti pada karang, lumpur, pasir, batu, mangrove dan benda keras. Selain benda mati, makroalga juga dapat melekat pada tumbuhan lain sebagai epifitik. Pertumbuhan makroalga yang melekat pada substrat sangat dipengaruhi oleh adanya sedimentasi (Littay, 2014). Salah satu kelompok mankroalga yang ditemukan menempel pada organisme lain ialah alga merah. Alga ini dapat ditemukan tumbuh pada daerah subtidal hingga daerah pasang surut, termasuk ditemukan menempel pada akar tumbuhan mangrove.

Observasi yang dilakukan oleh West et.al., (2013), di Pasifik Barat menemukan berbagai jenis makroalga dari kelompok alga merah antara lain yaitu Acrochaetium globosum, Colaconema sp., Bostrichya tenella, Caulaconthus indicus, Murrayella periclados, dan Caloglossa ogasawaraensis. Beberapa alga merah juga ditemukan di Australia dan New Zealand diantaranya yaitu Calaglossa monosticha, Calaglossa ogasawaraensis, Caloglossa postiae, Caloglossa leprieurii, Bostrychia moritziana, Bostrychia tenuissima dan Caloglossa leprieurii. Alga merah ini dijumpai tumbuh menempel pada akar mangrove Avicennia sp (King and Puttock, 1994). Sementara itu, keberadaan alga merah pada hutan mangrove Indonesia sangat sedikit dilaporkan. Padahal, Indonesia memiliki luasan wilayah hutan mangrove yang sangat tinggi dibanding Negara lain yang telah mengekspolasi keanekaragaman alga merah yang tumbuh di hutan mangrove. Ekplorasi keanekaragaman alga merah yang tumbuh di hutan mangrove perlu dilakukan sebagai data awal yang akan digunakan bagi pengembangan pemanfaatan selanjutnya.

Salah satu potensi yang dimiliki oleh makroalga merah yang tumbuh di hutan mangrove ialah sebagai sumber senyawa pelindung kulit. Karsten et al (2000) mengungkapkan bahwa terdapat berbagai senyawa yang terdapat pada alga ini yang memiliki potensi untuk dikembangkan selanjutnya sebagai produk pelindung kulit. Beberapa senyawa yang dihasilkan diantaranya ialah MAA-, Myco-Gly, MAA-2, Shinorine, Porphyra-334, Palythine, Asterina-330, Palythinol. Senyawa ini bersumber dari empat genus yaitu Bostrychia, Catenella, Caloglossa dan Stictosiphonia.

Oleh karena besarya potensi yang dimiliki oleh alga merah yang tumbuh dihutan mangrove, maka eksplorasi keanekaragaman secara perlahan dan terus-menerus penting untuk dilakukan. Salah satu lokasi yang dipilih sebagai lokasi awal eksplorasi ialah teluk serewe. Eksplorasi diawali dengan survei awal 
yang dilakukan pada bulan Juni-Juli 2015. Jumlah alga merah yang ditemukan pada akar mangrove di Teluk Serewe Kabupaten Lombok Timur sebanyak 8 spesies, terdiri dari 4 spesies dari genus Bostrychia, 3 spesies dari genus Caloglossa dan 1 spesies dari genus Stictosiphonia. Survei awal yang dilakukan, juga memberikan gambaran kondisi hutan mangrove Serewe Kabupaten Lombok Timur masih bagus. Mangrove di Teluk Serewe adalah bagian penting dari ekosistem manrove di pantai Selatan Lombok Timur dan jumlah spesies mangrove di pantai Selatan Lombok Timur sebanyak 10 spesies yaitu: Avicennia marina, Avicennia lanata, Bruguiera cylendrica, Ceriops decandra, Lumnitzera rasemosa, Rhizophora apiculata, Rhizophora mucronata, Rhizophora stylosa, Sonneratia alba, dan Xylocarpus moluccenis (Idrus et al., 2017). Oleh sebab itu, sangat dimungkinkan untuk mendapatkan jumlah spesies yang lebih banyak.

\section{Bahan dan Metode}

Alat dan bahan yang digunakan dalam penelitian ini, yaitu mikroskop cahaya dan mikroskop sterio, kaca benda, cawan petri, formalin $4 \%$, pinset, tissue, kutek bening. Penelitian bersifat deskriptif ekploratif,

pengambilan sampel dilakukan pada bulan Sepetember-Oktober 2015. Pengambilan sampel dan penentuan stasiun penelitian menggunakan metode purposive sampling (Gambar 1.). Pemilihan lokasi didasarkan pada arah mata angin serta letaknya dibandingkan dengan daerah pasang surut. Pengamatan dilakukan di Laboratorium Biologi Dasar dan Laboratorium Imunologi.

Pengambilan sampel dilakukan tanpa menggunakan metode sampling menggunakan transek, tetapi pengambilan sampel dilakukan secara acak pada pneumatofor mangrove yang ditemukan keberadaan alga epifit. Preparasi di lapangan dilakukan dengan mengawetkan sampel menggunakan formalin $4 \%$. Pengawetan dilakukan untuk menghindari kerusakan sampel sebelum selesai pengamatan di laboratorium. Pengamatan yang dilakukan meliputi pengamatan karakter morfologi untuk memudahkan proses identifikasi. Identifikasi sampel mengacu pada jurnal yang ditulis oleh King and Puttock (1994), (Kamiya et.al., 2003), dan buku algae (Taylor, 1979). Analisis data dilakukan dengan mendeskripsikan hasil penelitiaan kemudian data disajikan dalam bentuk table dan gambar. 


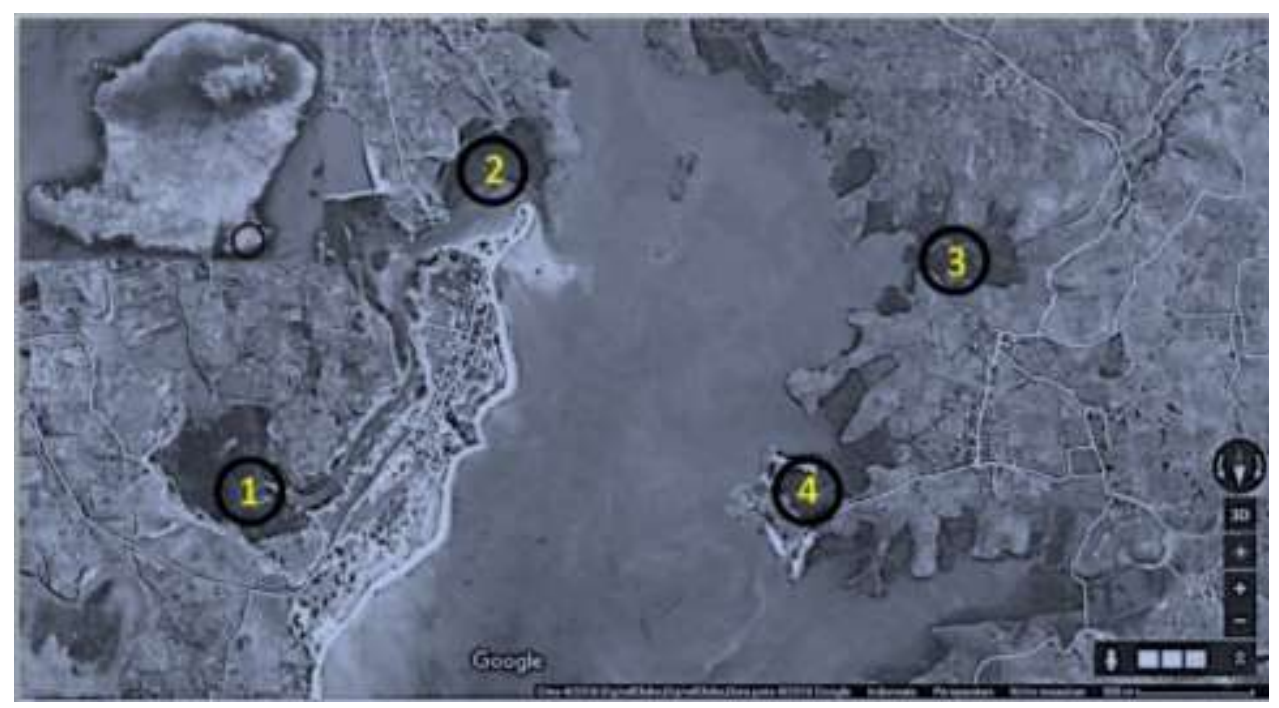

Gambar 1. Lokasi pengambilan sampel (Teluk Serewe Kabupaten Lombok Timur), Angka 1,2,3 dan 4 menunjukkan stasiun tempat pengambilan sampel.

\section{Hasil dan Pembahasan}

\section{Diversitas Jenis Makroalga Merah Hutan Mangrove Teluk Serewe}

Berdasarkan hasil penelitian yang dilakukan di Teluk Serewe Kabupaten Lombok Timur. Alga merah yang ditemukan sebanyak 11 spesies, yaitu 5 spesies dari genus Bostrychia, 1 spesies dari genus Stictosiphonia yang termasuk kedalam famili Rhodomelaceae,
3 spesies dari genus Caloglossa termasuk kedalam famili Delesseriaceae, 1 spesies dari genus Gelidium termasuk kedalam

Gelidiaceae, sedangkan 2 spesies dari genus Catenella termasuk kedalam famili Caulacanthaceae (Tabel 1.). Spesies yang ditemukan merupakan spesies yang umum ditemukan di hutan mangrove. West et.al., (2013) dalam observasinya didaerah pasifik barat menemukan jenis alga merah yang sama.

Tabel 1. Alga merah yang ditemukan pada Stasiun Penelitian

\begin{tabular}{llcccc}
\hline & & \multicolumn{4}{c}{ Stasiun } \\
\cline { 2 - 6 } No. & Nama & $\mathbf{1}$ & $\mathbf{2}$ & $\mathbf{3}$ & $\mathbf{4}$ \\
\hline 1. & Bostrychia moritziana & + & + & + & + \\
2. & Bostrychia scorpiodes & + & - & - & - \\
3. & Bostrychia radicans & + & + & + & + \\
4. & Bostrychia tenella & + & + & + & + \\
5. & Caloglossa leprieurii & + & - & - & - \\
6. & Caloglossa intermedia & + & + & + & + \\
7. & Caloglossa continua & + & - & - & + \\
8. & Stictosiphonia gracilis & + & - & - & - \\
9. & Catenella sp. & + & + & + & + \\
\hline
\end{tabular}


10. Catenella nipae

11. Gelidium crinale
Jumlah spesies paling banyak ditemukan pada stasiun, yaitu sebanyak 10 spesies. Sepuluh spesies tersebut antara lain: Bosrychia moritziana, $B$. scorpiodes, $B$. radicans, $B$. tenella, Caloglossa leprieurii, C. intermedia, $C$. continua, Stictoshiponia gracilaris, Catenella nipae dan Cantenella sp.. Stasiun ini merupakan stasiun yang paling jauh jaraknya dengan bibir pantai. Paling singkat tergenang air tawar dan paling cepat terkena dengan air tawar. Kondisi lingkungan memungkinkan alga merah untuk ditemukan tumbuh di lokasi tersebut. Alga merah hutan mangrove tumbuh pada lokasi yang memiliki kadar garam rendah, sehingga alga ini umumnya ditemukan pada bagian belakang formasi mangrove yang dekat dengan daratan.

Pada Stasiun 2 ditemukan sebanyak 7 spesies alga merah. Tujuh spesies tersebut yaitu Bostrychia moritziana, B. radicans, B. tenella, Caloglossa intermedia, Catenella nipae, Catenella sp. dan Gelidium crinale. Sementara itu, jumlah spesies dan jenis spesies yang ditemukan pada stasiun 3 sama dengan jumlah spesies dan jenis spesies pada stasiun 4. Jika dibandingkan dengan stasiun 2 maka, perbedaannya hanya terletak pada keberadaan Gelidium crinale pada stasiun 2, selebihnya spesies yang ditemukan sama. Stasiun 2, 3 dan
4 memiliki tingkat kemiripan spesies yang tinggi. Bahkan pada stasiun 3 ditemukan spesies yang sama persis dengan stasiun 4 .

Kesamaan jenis spesies yang ditemukan pada ketiga stasiun menunjukkan bahwa ketiga stasiun tersebut memiliki karakteristik habitat yang sama. Berdasarkan hasil pengamatan secara langsung, karakteristik ketiga lokasi memiliki kesamaan dari 4 hal. Empat hal tersebut adalah 1. Jarak dengan pesisir, 2. Intensitas tergenang oleh air laut, 3. Substrat dan 4. Jenis mangrove. Stasiun 2,3 dan 4 berbatasan langsung dengan wilayah lautan sehingga intensitas tergenang oleh air laut sangat tinggi. Sementara alga yang hidup pada akar mangrove umumnya berada pada posisi yang jauh dari wilayah laut atau dekat dengan daratan. Dari sisi substrat, ketiga lokasi (stasiun 1, 2 dan 3) memiliki substrat dengan kandungan lumpur yang lebih tinggi dibandingkan dengan stasiun 1. Kondisi substrat memungkin stasiun 1, 2 dan 3 memiliki jenis alga yang sama. Terlebih lagi, pada ketiga stasiun jenis mangrove yang mendominasi ialah Rhizophora $\mathrm{sp}$, sementara pada stasiun1 didominasi oleh Avicenia sp dan Soneratia sp. Karakteristik ketiga stasiun yang sangat mirip memungkinkan unsur hara dan nutrisi yang terkandung relative sama. Barus (2002) 
mengungkapkan bahwa kesamaan unsur hara dan nutrisi memungkinkan dua lokasi yang berbeda memiliki kesamaan spesies yang tinggi.

Secara umum jumlah spesies yang temukan mirip dengan jumlah spesies yang didapatkan oleh King and Puttock (1994) di New South Wales dan West (2013) di Pacifik barat. Secara umum jumlah spesies alga yang dapat tumbuh pada hutan mangrove memang terbatas. Keterbatasan ini disebabkan oleh

\section{Karakteristik Alga Merah (Rhodophyta)}

Spesies alga merah yang ditemukan pada akar mangrove di Teluk Serewe Kabupaten Lombok Timur yaitu Bostrychia moritziana, Bostrychia scorpiodes, Bostrychia radicans, Bostrychia tenella, Caloglossa leprieiurii, Caloglossa continua, Bostrychia simpliciuscula, Geladium crinale, Stictosiphonia gracilis, Catenella nipae, Catenella $\mathrm{sp}$

1. Bostrychia moritziana (King and Puttock, 1989).

Bostrychia moritziana termasuk ordo Ceramiales, spesies ini memiliki warna merah kecoklatan, talus silinder, terdapat percabangan primer dan sekunder, ujung talus alternate, pada cabang utama terdapat sel polysiphonus dengan 3 deretan sel perisentral. Tingkatan deretan sel perisentral ke 5-6 akan terbentuk percabangan lateral atau percabangan samping, kondisi hutan mangrove yang tergolong akstrim, baik intensitas cahaya yang sampai ke dasar hutan, intensitas genangan maupun masukan air tawar dari wilayah daratan. Meskipun demikian pada beberada daerah dapat dijumpai lebih banyak spesies alga merag. Coppejans dan Galin (1989) menemukan 22 spesies yang menempel pada akar Ceriops sp, Avicenia sp dan Sonneratia sp di Kenya.

sedangkan percabangan samping memiliki sel perisentral sebanyak 2 deretan sel. Karakteristik dari Bostrychia moritziana, yaitu terdapat sel monoshiponous pada setiap ujung talus sebagai tempat perkembangbiakan secara vegatatif (Gambar 2. No 1 dan 2).

2. Bostrychia scorpiodes (King and Puttock, 1989).

Bostrychia scorpiodes termasuk pula dalam ordo Ceramiales dengan talus silinderis, memiliki warna ungu kecoklatan, bagian ujung talus mengalami pembengkakan yang disebut dengan stichidia, yaitu tempat terbentuknya spora untuk perkembangan spesies Bostrychia scorpiodes. Spora berkumpul hampir memenuhi bagian tengah stichidia yang berbentuk bulat memanjang. Holdfast pada spesies ini terpisah, memiliki percabangan primer dan sekunder. Percabangan dicotomus, setiap percabangan utama akan muncul holdfast. Tiga deretan sel 
perisentral yang tersusun rapi, satu deret sel perisentral akan membentuk percabangan lateral, pada percabangan lateral terdapat 3 deretan sel perisentral yang tersusun rapi kearah ujung talus. Karakteristik dari spesies ini terdapat pembengkakan pada percabangan dikotom serta ujung talus alternate dengan sedikit melengkung kedalam (Gambar 2. No 3 dan 4).

\section{Bostrychia radicans (King and} Puttock, 1989).

Talus silinderis, percabangan monopodial, memiliki cabang utama dan cabang sekunder, bagian apikal talus bercabang dikotom. Holdfast serabut, terlihat 4 deret sel perisentral yang beraturan, percabangan samping memiliki 4 deret sel perisental, cabang sekunder terbentuk pada setiap 5-6 tingkatan sel perisentral, ujung talus polyshiponous yaitu memiliki sel lebih dari 1 terlihat ada 3 deret sel persentral (Gambar 2. No 5 dan 6).

4. Bostrychia tenella (King and Puttock,1989).

Talus prostate dengan percabangan pinnate alternate, memiiki 5 deretan sel perisentral, pada setiap percabangan lateral polyshiponous sedangkan semua percabangan sekunder monosiphonous, tetraspora pada spesies ini belum matang, akan tetapi tetraspora terbentuk pada ujung talus sel monoshiponous. Holdfast langsung dari cabang utama, warna talus merah pekat (Gambar 2. No 7).

5. Caloglossa intermedia (Kamiya et.al., 2000).

Talus menyerupai blade yang datar, percabangan ujung talus dikotom, terdiri dari 3 deret sel perisental yang panjang dan tebal dibagian tengah, terlihat bagian sel lateral melebar kearah samping dengan bentuk sel terputus-putus dengan sederetan sel. Holdfast terpisah, muncul pada setiap percabangan. Spora berkumpul rapat di ujung talus (Gambar 2. No 8)

6. Caloglossa leprieurii (King and Puttock, 1994).

Hampir semua spesies dari Caloglossa memiliki bentuk talus seperti blade yang lebar dan tipis, terdiri dari 3 deret sel perisental menebal seperti pelepah, sel laterall melebar, karakter pada spesies Caloglossa leprieurii bentuk seperti tanaman hias kecil, dengan holdfast terpisah dekat dengan talus, terlihat jelas antara gametofit jantan dan betina. Gametofit jantan ditandai dengan tidak adanya percabangan pada ujung talus, sedangkan untuk gametofit betina terdapat percabangan dikotomus kecil pada bagian ujung talus (Gambar 2. No 9). 


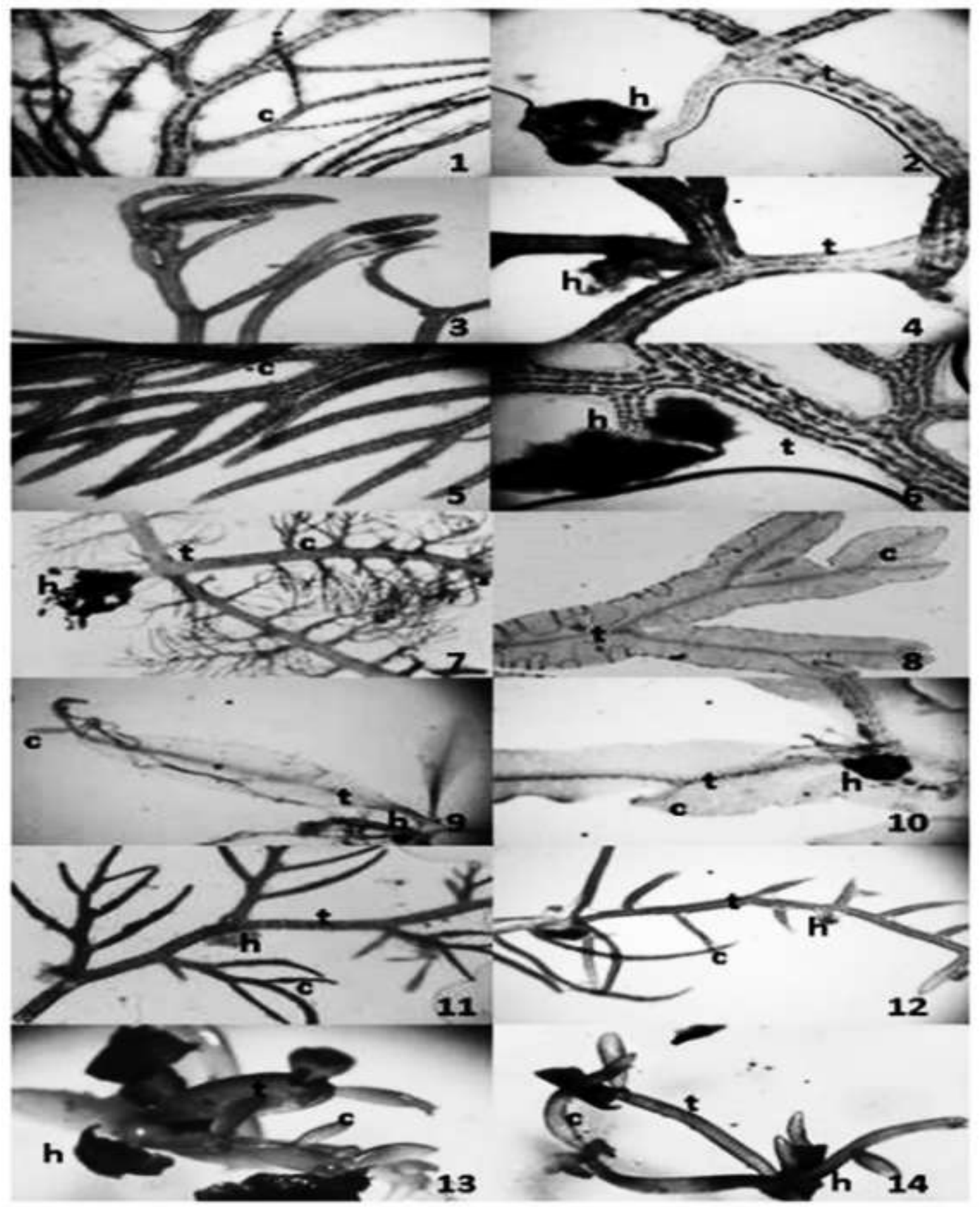

Gambar 2. Jenis Alga Merah yang ditemukan di hutan mangrove Desa Serewe, Kecamatan Jerowaru, Kabupaten Lombok Timur. 1 dan 2 Bostrychia moritziana, 3 dan 4 Bostrychia scorpiodes, 5 dan 6 Bostrychia radicans, 7. Bostrychia tenella, 8. Caloglossa intermedia, 9. Caloglossa leprieurii, 10. Caloglossa continua, 11. Stictoshiponia gracilis, 12. Gelidium crinale,13. Catenella nipae ,14. Catenella sp. , h. Holdfast, t. Talus utama, c. Cabang talus. 
7. Caloglossa continua (King and 10. Catenella nipae

Puttock, 1994).

Talus menyerupai daun atau blade, holdfast tidak menyatu muncul disetiap cabang dikotom, sel perisentral seperti pelepah kemudian melebar kearah samping. Percabangan ujung talus pada spesies ini dikotomus, karakteristik terdapat titik tumbuh talus baru berada pada bagian tengah percabangan dikotom talus (Gambar 2. No 10). 8. Stictoshiponia gracilis (Kamiya et.al., 2000).

Talus silinder sampai membentuk lempeng, percabangan monopodial, memiliki 4 sel perisentral, terdapat percabangan primer dan percabangan sekunder, percbangan primer terbentuk dari 2 sel perisentral. Pada percabangan primer terdapat 3 sel perisentral, sedangkan percabangan sekunder muncul diantara 6-9 tingkatan sel perisentral, pada percabangan primer dengan 2-3 sel perisentral, stichidia terbentuk pada bagian ujung talus yang melengkun. Holdfast terbentuk dari 2 deret sel perisentral cabang primer (Gambar 2 . No 11).

\section{Gelidium crinale}

Holdfast serabut, talus silinderis, beberapa talus bercabang seperti terdapat tonjolan kecil. Ujung talus melengkung, lancip dan ada pula yang membulat. Gelidium crinale memiliki warna ungu sampai ungu pekat (Gambar 2. No 12).
Bentuk talus silinder, memiliki warna ungu, setiap holdfast terbentuk percabangan, genus Catenella ini menempel sangat kuat pada substratnya. Percabangan lateral tidak ada, biasanya terdapat percabangan pada ujung talus, terlihat seperti lingkaran pada bagian apical talus, ujung percabangan terdapat 3 tonjolantonjolan kecil. Holdfast serabut menyatu tidak langsung tumbuh menempel dengan talus (Gambar 2. No 13).

\section{Catenella sp.}

Talus silinder panjang dan tebal, percabangan tidak beraturan kesegala arah, warna pada spesies ini ungu muda, terdapat percabangan lateral yang merupakan tempat terbentuknya spora, spora menyebar pada subapikal cabang lateral, holdfast pada Catenella sp. serabut menyatu menempel dekat dengan talus (Gambar 2, no.14).

\section{Kesimpulan}

Berdasarkan hasil penelitian dan pembahasan, dapat diambil kesimpulan sebagai berikut :

a. Alga merah (Rhodophyta) yang ditemukan melekat pada akar mangrove di Teluk Serewe Kabupaten Lombok Timur sebanyak 11 spesies dari 5 genus yaitu 4 spesies dari genus Bostrychia, 3 spesies dari genus Caloglossa, 2 spesies dari genus Catenella, 1 
spesies dari genus Stictosiphonia dan 1 spesies dari genus Gelidium.

b. Alga merah yang terdapat pada akar mangrove, memiliki bentuk talus silindris (Bostrychia, Stictosiphonia, Catenella dan Gelidium ) dan seperti daun (blade) (Caloglossa), percabangan dikotom atau monopodial dan susunan sel polysiphonous, holdpast berbentuk cakram dan serabut.

\section{Daftar Pustaka}

Barus, T.A. 2002. Pengantar Limnologi. Fakultas MIPA USU. Medan: iii+264 hlm.

Budhiman, S. Ratih, D. Cecep, K. Nining, P. 2001. Kerusakan Hutan Mangrove di Pulau Lombok Menggunakan Data Landsat-TM dan Sistem Informasi Geografis (SIG). Jakarta: Pemanfaatan dan Teknologi Penginderaan Jauh (PUSBANGJA) LAPAN.

Coppejans E dan Galin E, 1989, Macroalgae assosiated with the mangrove vegetation of Gazi Bay (Kenya), Bull. Soc. Roy. Bot. Belg.122: 47-60

Idrus, Al-A., Syukur, A., Zulkifli, L., 2017. Konservasi Mangrove Berbais Institusi Masyarakat Lokal di Pesisir Selatan Lombok Timur. Laporan Penelitian. Fakulatas Keguruan dan Ilmu Pendidikan Universitas Mataram.

Jhon, West. A., Mitsunobu Kamiya., Susan Loiseaux D.G., Ulf Karsten., Giuseppe C. Zuccarello. 2013. Observations On
Some Mangrove-Associated Algae From The Western Pacific (Guam, Chuuk, Kosrae, And Pohnpei). Algae. 28(3): 241-266

King, R.j and Puttock, C.F. 1989. Morfhology and Taxonomy of Bostrychia and Stictoosiphonia

(Rhodomelaceae/Rhodophyta). Aust. Syst. Bot. 2. 1-73

King, R.J and Puttock, C.F. 1994. Morphology and Taxonomy of Caloglossa (Delesseriaceae, Rhodophyta). Australia: University of New South Wales.

Kamiya, Mitsunobu., Giuseepe C.Z., Jhon A.West. 1994. Reproductive Structures Of Bostrychia Simpliciuscula (Ceramiales, Rhodophyceae) In The Field And In Culture. Jpn. J. Phycol (Sorui). 42: 165-174.

Kamiya, Mitsunobu., 2000. Caloglossa Intermedia sp. Nov (Rhodophyta) From The Westren Atlantic Coast: Molecular and Morfhological Analyses Whit Special Refrence to Calogloss leprieurii and Caloglossa monostica. J.Pychol. 38, 411-420

Kuenzer, C., Bluemel, A., Gebhardt, S., Quc., T.V, and Dech, S. 2011. Remote Sensing of Mangrove Ecosystem: $A$ Review. Remote Sensing 3: 878-928.

Littay, Christina. 2014. Sebaran dan Komunitas Makro Alga Di Perairan Teluk Ambon. Jurnal Tekonologi Kelautan Tropis, Vol. 6, No. 1, Hlm. 131-142. 
Sukardjo, S., 2004. Fisheries Associated with Mangrove Ecosystem in Indonesia. A
View from a Mangrove Ecologist. BIOTROPIA23:13-2. 